\title{
Colleges informationization construction project analysis and evaluation
}

\author{
Zhang Jing \\ Department of Electronics Science and Technology \\ China Maritime Police Academy \\ Ningbo ,China \\ E-mail: theliumeng@163.com
}

\author{
Liu Meng \\ Department of Logistics management \\ China Maritime Police Academy \\ Ningbo ,China
}

\begin{abstract}
This article through the domestic and international information level measurement methods, draw out college information level evaluation problems to be solved, information level of colleges factors analysis, fuzzy analytic hierarchy process is used to construct the evaluation system, the informatization construction of our evaluation system research ideas and research significance.
\end{abstract}

\section{Keywords- Project management; Colleges informatization level; Evaluation}

\section{INTRODUCTION}

Information construction in China's current college one of the important contents of construction, informationization level is measured colleges modernization level of important symbol. Information level of qualitative and quantitative analysis and help to informationization construction to scientifically and objectively evaluate, better understand the information development level and promote the construction of the ability. This paper is based on this objective, combined with the ongoing college information construction, so this preliminary research object, elements analysis, and put forward the overall level of college information analysis and evaluation of evaluation system, through the actual use of improvement, used in other colleges information construction level evaluation..

\section{THE INFORMATIONIZATION LEVEL MEASUREMENT METHODS AT HOME AND ABROAD AND BRIEFLY}

Domestic and foreign information level measure this information development level analysis method of the research in China's current information with the high-speed development of the objective request, through the statistical analysis of information index, quantitatively measure over the information development degree and efficiency, and can improve the government to promote information construction decision-making more scientific and accuracy, make macro decision department and industry management department can effectively guide and promote the information construction work, study and establish information for economic and social development plan to offer quantization, scientific basis, and then driving the country and area's economic and social development..

Information level calculate began in the $1960 \mathrm{~s}$, the application of some of the theoretical model of information evaluation or method is currently has more mature, many evaluation system has long been the countries all over the world. From at home and abroad in recent years of measure the look, more representative of some famous scholars mainly by the method of design and international organizations, are summed up and see we have the following several kinds. One is the mark LuPu-Paula's statistics measure method. It is the use of statistical method of characteristics, according to specific departments and environmental concerns the distribution and structure information elements, the current world universal use this law to measure the information economy. But mark LuPuPaula, in statistical method has obvious flaw, such as information industry extension is too broad, will be the second industry of department is also included; And because the information department will exclude information activities, indirectly reflect the social information level, and the computation are too complex to often. 2 it is information index model and on the basis of statistics, and rolled into a general index, from the information flow and measuring social information ability to reflect the social information level. Information index method and says information index model. This method was later, caused the world attention has also been the favour of all countries. Information index method mainly from the post and telecommunications, broadcasting and TV news industry information, information equipment was selected, communication, information coefficient of the main body level four elements to reflect social information Three is to construct the index system of information method. According to the national economic development level, the information level and the level of information imbalance, the establishment of an information to the appraisal system of evaluation. Information index system of rough set is not fine, outstanding applicability and operability, comparative. Our government has enacted a special national information index system. This method will information index set to five kinds of 20 indicators, is the current measure and evaluate the information level is feasible frame of reference. The common method of evaluation expert evaluation, divided into economic model method, the mathematical evaluation method and the combination model method and so on four major categories.

\section{INFORMATION LEVEL ASSESSMENT TO SOLVE THE PROBLEMS}

Based on the information testing methods were introduced in this paper, the main process of analysis in solving the following questions: 
i evaluation objects segmentation and integration problems: namely the attributes of the information evaluation division and integrated evaluation classification guidance. Only to evaluation object decomposition, from several different levels and different assessment of direction, can we reach a detailed has theoretical and practical value of the evaluation results.

ii the evaluation standards and application: namely evaluation standard of information, to application in specific environment evaluation of information level through the case study and evaluation, and continuously improve, gradually formed more popular information evaluation standard, thus applied to more enterprise or industry information level of evaluation, this will greatly improve current information level evaluation research lagging behind the situation.

iiiand the evaluation method of reference and innovation: to analyze the evaluating method, combining with the specific situation of the evaluation objects to choose the appropriate evaluation method. In addition to reference the existing research findings in the field of outside, still need information elements according to characteristics of the original methods to improve or create a new evaluation method.

iv appraisal system analysis and construction: only according to a level or a certain level of evaluation knowledge is not a very good handle of the evaluation work, there is no form a reasonable set of perfect can reflect the enterprise or industry information level of internal and external characteristics of evaluation system.

$\mathrm{v}$ the quantitative evaluation model and build problem: lack of able to reflect a more comprehensive assessment information of quantitative evaluation model. This model not only can measure a evaluation object the size of the information level, and be able to it as the basis, the evaluation objects description in the particular case of all kinds of information strategy choice.

Information evaluation is a constant development and improvement of the field. As the evaluation can be premature, extremely likely negative effects, so for enterprise or industry the information level of any formal evaluation will gradually, and can't get rich quick. With the information level evaluation theory and method of the development and improvement, evaluation to improve the enterprise or the industry in the role of information ability will be fully manifests, people to the understanding of the information evaluation work will continue to deepen. Colleges information level evaluation also belong to the information evaluation, follow the basic method and information evaluation theory, therefore, can draw lessons from the above-mentioned information measurement methods, at the same time in the information level evaluation should also pay attention to solve the above analysis mentioned in the key problem.

\section{THE MAIN RESEARCH IDEAS}

Based on the information testing methods were introduced in this paper, the main process of analysis in solving the following questions:

i evaluation objects segmentation and integration problems: namely the attributes of the information evaluation division and integrated evaluation classification guidance. Only to evaluation object decomposition, from several different levels and different assessment of direction, can we reach a detailed has theoretical and practical value of the evaluation results.

ii the evaluation standards and application: namely evaluation standard of information, to application in specific environment evaluation of information level through the case study and evaluation, and continuously improve, gradually formed more popular information evaluation standard, thus applied to more enterprise or industry information level of evaluation, this will greatly improve current information level evaluation research lagging behind the situation.

iiiand the evaluation method of reference and innovation: to analyze the evaluating method, combining with the specific situation of the evaluation objects to choose the appropriate evaluation method. In addition to reference the existing research findings in the field of outside, still need information elements according to characteristics of the original methods to improve or create a new evaluation method.

iv appraisal system analysis and construction: only according to a level or a certain level of evaluation knowledge is not a very good handle of the evaluation work, there is no form a reasonable set of perfect can reflect the enterprise or industry information level of internal and external characteristics of evaluation system.

$\mathrm{v}$ the quantitative evaluation model and build problem: lack of able to reflect a more comprehensive assessment information of quantitative evaluation model. This model not only can measure a evaluation object the size of the information level, and be able to it as the basis, the evaluation objects description in the particular case of all kinds of information strategy choice.

Information evaluation is a constant development and improvement of the field. As the evaluation can be premature, extremely likely negative effects, so for enterprise or industry the information level of any formal evaluation will gradually, and can't get rich quick. With the information level evaluation theory and method of the development and improvement, evaluation to improve the enterprise or the industry in the role of information ability will be fully manifests, people to the understanding of the information evaluation work will continue to deepen. Colleges information level evaluation also belong to the information evaluation, follow the basic method and information evaluation theory, therefore, can draw lessons from the above-mentioned information measurement methods, at the same time in the information level evaluation should also 
pay attention to solve the above analysis mentioned in the key problem. Information evaluation, it is to point to evaluation body (that is, the information construction leading organ, scientific research institutions, etc.) according to a certain evaluation purpose and standards, the adoption of appropriate methods to evaluate the object technology (information level) understanding the value of evaluation process. information evaluation system is mainly including information $n$ evaluation index system is established and the establishment of the information evaluation method. Evaluation body, evaluation object, the evaluation standards this a few basic elements of organic combination become a evaluation system. For a particular evaluation, once the corresponding evaluation system was determined, the evaluation will become according to established steps "measure" problem. The process of evaluation is the basic elements of the gradually determine process.

Colleges the basic content of information, including the technology safeguard information, teaching safeguard information, infrastructure information, information policy and regulations technical standard, the command information, etc. Through the research of information content, on the understanding of the essence of information based on the content just may construct information level evaluation index system, further research information construction theory, analyses the influence factors of the information level, according to the characteristics of the index system of information construction, to construct the evaluation body of the characteristics of the information construction of information level evaluation index system.

Information evaluation index is information evaluation system research core science reasonable configuration evaluation index is the precondition of the information evaluation. Research from the main ideas of the elements of determined information, this paper analyzes the logic relationship between them to determine the index. information evaluation index allocation, in choosing proper indexes of the information construction after evaluation system. At the same time as information evaluation are many methods, fuzzy analytic hierarchy process to choose. The reason is that the choice because the analytic hierarchy process (ahp) is applied to a mature multi-level and problems of the comprehensive evaluation criterion scientific method, and fuzzy mathematics is qualitative indexes of quantitative processing effective means, so in colleges and universities information level of overall evaluation characteristic, this subject adopts fuzzy ahp evaluation.

\section{RESEARCH SIGNIFICANCE}

One is the information construction of colleges and universities theory innovation and deepening. Information construction in the new period is the core content of the construction of colleges and universities. Information evaluation system is the information construction is an important part of the theory. Because our country the development of information start later, these a few years are in the great-leap-forward development stage, information evaluation work is just unfolds, the less research material also is referring to all kinds of literature, and also not into the method of system system appear. This subject will be to information level evaluation system beneficial exploration, improve the level of information development reflects the index system, collect the relevant data, improving the evaluation method, scientific and objective information level measurement, the information construction of colleges make feasible information development strategy and related policy has a very important significance in theory and practice, not only is to existing information construction the beneficial supplement of the theory, and to evaluate the information level provide scientific theory.

It is to improve information construction of scientific decision-making and management level of profound strategic significance and the important practical significance. Through the scientific evaluation, and know the information construction of achievements and existing problems, measure and the gap between the development goal, not only for fix and adjust the construction plans to provide basis for improving the precision of the decision, and also can promote the information construction, speed information construction process.

Based on this objective, in the system at home and abroad based on the theory of information, according to the concrete characteristics of information construction of colleges and universities, and puts forward a reasonable evaluation index system and quantitative evaluation method, and based on the index system and methods of information level measurement and evaluation, in order to develop and coordinate information development strategy to provide the scientific basis for the quantitative

\section{REFERENCES}

[1] JiangAiLin. The level of informationization of different calculation methods [J]. Journal of finance in guangxi university. 2003.

[2] Yang cheng, wang jun, sun jl. Informatization logistics introduction [M]. Sichuan university press. 2010, 4-

[3] hu mans valley. The information industry development level of evaluation method and index system [J]. Journal of intelligence. 1999 4648-48.

[4] DengXiaoZhao, WuXiaoOu etc. Concerning informatization index system of several theory study [J]. Journal of intelligence. 2003, 4-

[5] the national informatization evaluation center. The national informatization level and analysis [M]. China accounting computerization. 2002. 